\title{
The concept of vocabulary teaching and studying
}

\section{Vazirakhon Rustamovna Ochilova}

\author{
PhD student \\ Uzbekistan State University of World Languages \\ e-mail: vazira.ochilova@gmail.com
}

\begin{abstract}
Vocabulary mastering is a critical part of foreign studying due to the fact the meanings of the modern-day phrases square degree often emphasized, whether or not or not in books or in classrooms. It is moreover imperative to guidance and is of predominate significance to a language learner. The recent evaluation suggests that teaching vocabulary is likewise complicated as a result of numerous teachers do not seem to be confident concerning pleasant apply in vocabulary teaching partner degreed now and then do no longer understand anyplace to start to make academic strain on word learning (Berne \& Blachowicz, 2008) In this newsletter. I summarize the important evaluation at the impotence of vocabulary and explaining numerous techniques employed by way of English lecturers once coaching English, still as my very own personal read of those troubles.
\end{abstract}

Key words: vocabulary, grammatical patterns, collocations, frequency, appropriateness.

\section{Introduction}

Vocabulary is of high-quality importance in expressing thoughts and thoughts in interplay activities. Vocabulary acquisition is the primary assignment of second language acquisition. This section will gift vocabulary teaching and gaining knowledge of the concept in connection with the take a look.

There are numerous theoretical studies on exploring the varieties of vocabulary expertise related to familiarity with a word (Richards (1976); Nation (1990); Carter (1992), and so on.) Richards (1976) made the primary try and listing the extraordinary kinds of understanding, which might be necessary to completely recognize a word. He changed into extra concerned with applicability to pedagogical exercise than attempting to provide a scientific framework for describing or accounting the word information (Meara, 1996). In the phrase information list, there has no strive to differentiate efficient vocabulary from the receptive vocabulary. Elaborating on Richards' list, he developed a list of diverse forms of vocabulary expertise that one have to own both receptively and productively on the way to have the whole command of a phrase:

1. The spoken shape of a

2. The written shape of a word

3. The grammatical styles of the phrase

4. The collocation conduct of the word

5. How common the word is

6. The appropriateness of a phrase

7. The conceptual that means of a word

8. The institutions a phrase has with different associated phrases

Richards (2001) also states that the expertise of a word may be divided into expertise regarding its shape (spoken/written), its function (grammatical patterns/collocations), its characteristic (frequency/appropriateness), and it is that means (idea/institutions). Accordingly, it is not the case that a word is either regarded or unknown. A word may be regarded in all types of degrees: from knowing, that given form of a present word to knowledge together with all four components referred to above. Those levels of phrase knowledge observe to native speakers as well as to second language acquisition beginners.

\section{Main part}

Similarly, to Richards and other, researchers have recommended their personal way of categorizing phrase knowledge. Carter (1992) has defined the same vocabulary expertise classes together with pronunciation, spelling, grammatical properties, syntactical functions, collocations, institutions, and senses, etc. Laufer (1997) categorizes phrase information as the form, the phrase shape, the syntactic sample of the word in a word or a sentence, that means, common collocations, and the lexical relations of the word with other phrases, consisting of synonym, antonym, and hyponym, and in the end common collocations.

Even though many researchers have classified vocabulary expertise in one-of-a-kind methods, there may be a consensus amongst them that vocabulary 
expertise is a complicated gadget that consists of numerous forms of vocabulary expertise besides that means and form. Any research that tends to discover vocabulary acquisition must regard it as its challenge to study the distinctive styles of word expertise, and most significantly, to explore the links and interrelationships among the extraordinary styles of phrase expertise (Schmitt and Meara, 1997:17-36).

Vocabulary plays a crucial position in expressing ideas and minds. The well-known British linguist, Wilkins (1976) says people should describe few matters without grammar, but they may express nothing without vocabulary. Widdowson (1987) thinks that the local English audio system can understand language fabric with correct vocabulary however not so proper in grammar regulations as opposed to those with correct grammar regulations but not so right in vocabulary use. Lord mentions that 'vocabulary is via some distance the maximum extensive and unmanageable factor within the mastering of any language, whether or not for an overseas or one's mom tongue because of lots of different meanings' (Lord, 1993, p. 83). Lewis (1992) holds the idea that vocabulary acquisition is the primary project of second language acquisition and language skills as listening; speaking, studying, writing, and translating all cannot pass without vocabulary.

Vocabulary coaching has been growing greatly because of 1980. Numerous specialists and linguists commenced being aware of vocabulary coaching during that period. For instance, in the 1980s Terrel proposed the herbal approach which emphasizes understandable and that means input in preference to grammatically correct production. In 1983, Allen mentions the presentation and exemplification of practical strategies inside the coaching of vocabulary. Later, in 1985, Ruth Gairn and Stuart Redman nation the ideas of vocabulary teaching. In 1997 Stockmen discusses the current trends in coaching second language vocabulary. He factors out those modern-day studies could advise that it is profitable to add specific vocabulary to the same old inferring activities inside the language study room.

Repetition is essential for vocabulary mastering because there may be a lot to recognize approximately every phrase that one meeting with it is not enough to benefit this data, and because vocabulary gadgets have to now not only be known, they have to be known well in order that they can be fluently accessed (2001, p. 74).

There are numerous approaches to expose the meanings of an English word, through such aids as (1) objects that can without problems be introduced to elegance(umbrellas, scissors, tools, buttons of many colors and sizes, and so on); (2) drawings by using the instructor and drawings with the aid of the students; (three) demonstrations to reveal actions(Allen, 1983, p. 41). Allen recommends teachers the use of the actual object on every occasion viable when displaying which means of an English noun.

Although vocabulary has been ultimately established as a crucial part of language acquisition, there square measure various problems to be taken into thought previously honestly considering the work and about to understand vocabulary. The first challenge would be to acknowledge precisely what it approaches to acknowledge a word. Ivor Armstrong Richards (1976) tries to handle this issue whereas he provides nine assumptions on what it involves to know a phrase. He says that understanding a word involves knowing the thanks to integrating it with completely different phrases, being alert to its linguistics capabilities moreover as linguistics behavior, derivations, and qualitative analysis with alternative phrases, not to say its extraordinary meanings. He in addition says:

... In preparing teaching material, we have a tendency, to begin with, a fashionable plan of vocabulary. The aim of vocabulary work has to be larger than sincerely masking a positive wide range of phrases on an inventory. Then we must always check out however teaching methods will facilitate understand our plan of what it means that to acknowledge a phrase (p. 88).

Nation (1990), too, has mentioned the extraordinary points to replicate on thought on whereas we have a tendency to speak just about gaining information of a word. He enhances Richards' (1976) assumptions and organizes a list of queries regarding the shape, feature, role, and that means of the word to reveal what is concerned in understanding a phrase (p. 31). Moreover, he subdivides vocabulary data into a receptive and effective understanding of a word. Palmberg (1990) says that vocabulary power keep with Faerch, Hasstrup, and Phillipson (1984) may be a "continuum among the capability to create feel of a word and capability to activate the phrase habitually for effective functions" (p. 1). It is going to come back to be a taxing venture to undertake and educate all parts of each phrase. For that reason, it's miles necessary that instructors decide what parts of the phrases to teach by means that of brooding about within the event that they need their newbies to use the phrases receptively or fruitfully.

The second concern is what words to coach. It might be the thought that low-frequency words square measure most likely the most problematic to novices. 
However, Levine and Reves (1990) nation that unusualness with standard vocabulary constitutes a much bigger drawback than technical phrases. Laufer (1998), as well, has discovered that standard vocabulary are often harder than jargon (p. 258). Some researchers believe that phrase-frequency counts are often one manner to cope with the difficulty of those words to teach. Nation (1990) suggests phrase-frequency counts together manner to select vocabulary to teach freshmen of English. Keep with him, frequency counts will assist instructors and direction designers in numerous approaches: "they may assist a coach to develop a way just about that phrases square measure helpful and ought to receive interest and which might be infrequent" (p. 19-20). However, he is aware that frequency counts can even gift troubles consisting of

1) Some relevant phrases that do not arise among the primary or second hundred phrases;

2) Some excessive- frequency words don't seem to be applicable for starting level inexperienced persons;

3) The varied lists do not regularly agree;

4) They will gift an unsuitable order to teach the phrases, and

5) They will no longer be as dependable on top of a precise degree.

Richard (1970) in addition mentions flaws in frequency counts: "instructors and path designers have usually had to dump the frequency lists and depend upon their terribly own discretion on those nouns to study" (p. 88). He proposes an inventory of a number of the matters to think about while preparing a list of phrases to teach newcomers of English frequency, language needs, accessibility, familiarity, and finding out burden.

The third essential hassle is the way to train so learners can learn the words additional effectively. What is going to be the first-rate methodology to vocabulary teaching that would facilitate newcomers gather words a lot of delicately and correctly? In wanting to answer this question Gairns and Redman (1986) kingdom that phrase frequency and recency of use square measure 2 of the most essential parts that have an effect on the storage and retrieval of foreign language (FL) words in a very rookies' intellectual lexicon (p. 88-89). Laufer and Shmueli (1997) advocate that to learn vocabulary one necessary issue is that the frequency of promotion. Country (1990) factors out that novices want five to seven exposures to a word to create sure gaining information of can occur sixteen or larger exposures could also be wanted among the case of implicit about to understand. Another methodology emphasizes the standard of the data processing as against the number. Quoting Schmidt (1990, 1992), Laufer and Shmueli say, "one of the conditions for transforming input into the consumption is noticing and about to the novel fabric" (p. 91). Palmberg (1990) indicates, "Novices' personal hobby appears to be the other applicable issue for the storage and retrieval of phrases. This may offer an evidence for why many phrases square measure additional obtainable than others" (p. 4). The conclusion drawn from those statements is that square measure many factors to mirror concerning the simplest way to show vocabulary, which beyond any doubt newbies' multiple exposures to the phrase play a necessary half among the strategy of the usage of a word simply and accurately. Taking all of those problems into thought, students and analysisers have equipped a diffusion of techniques and methods to assist freshmen research vocabulary. One in every of the foremost fashionable ways in which of dealing with L2 vocabulary among rookies is to use bilingual dictionaries. Researchers have divergent critiques on the subject. Laufer and Shmueli (1997) say that a have a glance at exploitation Atkins and Knowles (1990) achieved in Europe terminated that 75 you look after language newbies use bilingual dictionaries. Laufer and Shmueli transfer that it does not imply bilingual dictionaries square measure higher. It is going to mean that newbies wish, psychologically, to depend upon their L1 (p. 93). Besides, their analysis has well tried that "Glosses in L1 well-tried to be a lot of helpful for retention scores than glosses in English" (p.103). A probable rationalization for this locating are often that novices may awareness completely of the new L2 phrase because of the L1 become absolutely acquainted (p. 103). Luppescu and Day (1993) have appeared into the position of bilingual dictionaries in vocabulary finding out while reading, and terminated, "the use of bilingual dictionaries while finding out will facilitate the about to understand of vocabulary by EFL students.”(p. 275). However, they have in addition determined some shortcomings:

1) Bilingual dictionaries could also be dishonorable thanks to a colossal variety of entries in various instances, and

2) Inexperienced persons can even pay doubly the time analyzing a matter content while the usage of dictionaries.

Schmitt (1997), too, calls interest to the in depth use of bilingual dictionaries, and he provides another drawback. Schmitt feedback that Tomaszczyk's 
subjects (1979) regarded the knowledge in bilingual dictionaries as usually less entire than monolingual dictionaries (p. 209ᄀ10). Prince (1996), instead, seems on the troubles of context and translation. In his have a glance at approximate context as against translation, he concludes that the weaker establishment finished higher whereas the keep in mind was by exploitation translation. He says, "Excessive advanced capability to be told words via translation links could in some cases be damaging to the institution of the talents and methods needed to cope with discourse" (p. 486). What is more, he says, "Context affords the thanks to determine the meaning of the novel phrase and no longer essentially the approach to learning it" (p. 489). He realizes that learning vocabulary through analyzing permits newcomers to expand methods as well as wanting forward to and inferring.

\section{Conclusion}

It in addition will increase newcomers' independence and consciousness of words in discourse for contact besides exposing them to samples of collocation. His previous finish is that context is essential but that newbies has to additionally isolate the word and study it very well.

\section{References}

* Graham, S. (1997). Effective language learning. Positive strategies for advanced level language learning.

* Jacobs, J. E., and Paris, S. G. (1987). “Children's metacognition about reading: Issues in definition, measurement and instruction." Educational Psychology, 22, 255-278.

* Khezrlou, S. (2012). "The Relationship between cognitive and metacognitive strategies, age and level of education". The Reading Matrix, 12(1), 50-61.

* Allen, V. F. (1983) Techniques in Teaching Vocabulary. Oxford: Oxford University Press.

* Berns, M. S. (1984) Contexts of Competence: Social and Cultural Consideration in Communicative Language Teaching. New York: Plenum Press.

* Carter, R. (1992) Vocabulary, Cloze and Discourse. Harlow: Longman.

* Carter, R. (1992) Vocabulary: Applied Linguistic Perspectives. London: Routledge.

* Coady, J. (1987) Research on ESL/EFL Vocabulary Acquisition: Putting it in Context. New York: Oxford University Press.

* Lewis, M. (1992) The Lexical approach London: Language Teaching Publications.

* Lewis, M. (1993) The Lexical Approach. England: Language Teaching Publications. 